\title{
REPRESENTATION OF A QUOTIENT OF SOLUTIONS OF A FOUR-TERM LINEAR RECURRENCE RELATION IN THE FORM OF A BRANCHED CONTINUED FRACTION
}

\begin{abstract}
The quotient of two linearly independent solutions of a four-term linear recurrence relation is represented in the form of a branched continued fraction with two branches of branching by analogous with continued fractions. Formulas of partial numerators and partial denominators of this branched continued fraction are obtained. The solutions of the recurrence relation are canonic numerators and canonic denominators of $\mathcal{B}$-figured approximants. Two types of figured approximants $\mathcal{A}$-figured and $\mathcal{B}$-figured are often used. A $n$th $\mathcal{A}$-figured approximant of the branched continued fraction is obtained by adding a next partial quotient to the $(n-1)$ th $\mathcal{A}$-figured approximant. A $n$th $\mathcal{B}$-figured approximant of the branched continued fraction is a branched continued fraction that is a part of it and contains all those elements that have a sum of indexes less than or equal to $n$. $\mathcal{A}$-figured approximants are widely used in proving of formulas of canonical numerators and canonical denominators in a form of a determinant, $\mathcal{B}$-figured approximants are used in solving the problem of corresponding between multiple power series and branched continued fractions. A branched continued fraction of the general form cannot be transformed into a constructed branched continued fraction. For calculating canonical numerators and canonical denominators of a branched continued fraction with $N$ branches of branching, $N>1$, the linear recurrent relations do not hold. $\mathcal{B}$-figured convergence of the constructed fraction in a case when coefficients of the recurrence relation are real positive numbers is investigated.
\end{abstract}

Key words and phrases: branched continued fraction, four-term recurrence relation.

\footnotetext{
${ }^{1}$ Pidstryhach Institute for Applied Problems of Mechanics and Mathematics, 3b Naukova str., 79060, Lviv, Ukraine

${ }^{2}$ Ternopil National Economic University, 11 Lvivska str., 46020, Ternopil, Ukraine

${ }^{3}$ Volodymyr Gnatiuk Ternopil National Pedagogical University, 2 Kryvonosa str., 46027, Ternopil, Ukraine

E-mail: i.bilanyk@ukr.net (Bilanyk I.B.), bodnar4755@ukr.net (Bodnar D.I.), lesyabuyak@ukr.net (Buyak L.M.)
}

\section{INTRODUCTION}

It is well known that the general solution of a linear homogeneous recurrence relation of second order: $y_{n}=b_{n} y_{n-1}+a_{n} y_{n-2}, n=1,2, \ldots$, where the $a_{n}, b_{n}, n \geq 1$, are complex numbers, can be represented in a form of a linear combination of two linearly independent solutions

$$
y^{(1)}=\left(1,0, y_{1}^{(1)}, y_{2}^{(1)}, \ldots\right), y^{(2)}=\left(0,1, y_{1}^{(2)}, y_{2}^{(2)}, \ldots\right) .
$$

These solutions are, respectively, canonical numerators and canonical denominators of approximants of the continued fractions $[15,18,19]$

$$
D_{k=1}^{\infty} \frac{a_{k}}{b_{k}}
$$

$\mathrm{y} \triangle \mathrm{K} 517.524$

2010 Mathematics Subject Classification: 11A55, 11J70, 30B70, 40A15.

(C) Bilanyk I.B., Bodnar D.I., Buyak L.M., 2019 
In this paper, an analogous idea for a four-term linear recurrence relation

$$
y_{n}=c_{n} y_{n-1}+b_{n} y_{n-2}+a_{n} y_{n-3}
$$

where the $a_{n}, b_{n}, c_{n}, n \geq 2$, are complex numbers, is considered.

Different constructions of multidimensional generalizations arise as a result of considering the $N$-term recurrent relation, $N>1,[8,12,18]$. They are widely used for compatible approximations, for representation of solutions of algebraic equations, etc. The formulas of the elements of these fractions were not obtained, in general, except for the Furshtenau's twodimensional generalization of continued fractions [14]. B. V. Krukowski has proved the theorem of convergence of these fractions [16].

This investigation leads to branched continued fractions (BCF) that are a multidimensional generalization of continued fractions. Thus, $\mathrm{BCF}$ of the general form are under consideration $[7,9,11,21]$. Also, the different forms of BCF exist, in particular, BCF of the special form [1, $3-6,10,13]$, two-dimentional continued fractions $[2,17,20]$, etc. The different constructions of their approximants [7] and, respectively, the different types of convergence appear in the considering of different mathematical problems.

Let

$$
\mathcal{I}=\left\{i(k)=\left(i_{1}, i_{2}, \ldots, i_{k}\right): 1 \leq i_{p} \leq 2, p=\overline{1, k}, k \geq 1\right\}
$$

be the set of multiindices. Let us introduse an order relation $\prec$ on the set $\mathcal{I}$ for $i(p) \in \mathcal{I}$ and $j(q), j(p) \in \mathcal{I}$, where $j(s)=\left(j_{1}, j_{2}, \ldots, j_{s}\right), s \in \mathbb{N}$ :

1) $i(p) \prec j(q)$, if $p<q$;

2) $i(p) \prec j(p)$, if $i_{1}<j_{1}$;

3) $i(p) \prec j(p)$, if exists $r, 1 \leq r<p$, such that $i_{k}=j_{k}, k=\overline{1, r}, i_{r+1}<j_{r+1}$.

Let we have sequenses of complex numbers $\left\{\xi_{i(k)}\right\},\left\{\eta_{i(k)}\right\}$, where $i(k) \in \mathcal{I}$, then

$$
\sum_{i_{1}=1}^{2} \frac{\xi_{i(1)}}{\eta_{i(1)}+\sum_{i_{2}=1}^{2} \frac{\xi_{i(2)}}{\eta_{i(2)}+\cdot}}=\sum_{i_{1}=1}^{2} \frac{\xi_{i(1)}}{\eta_{i(1)}}+\sum_{i_{2}=1}^{2} \frac{\xi_{i(2)}}{\eta_{i(2)}}+\ldots=D_{k=1}^{\infty} \sum_{i_{k}=1}^{2} \frac{\xi_{i(k)}}{\eta_{i(k)}}
$$

be a general branched continued fraction with two branches of branching with complex elements.

A $n$th approximant of the BCF (2) is a finite BFC of the form

$$
f_{n}=D_{k=1}^{n} \sum_{i_{k}=1}^{2} \frac{\xi_{i(k)}}{\eta_{i(k)}}, n \geq 1 .
$$

The continued fraction

$$
\frac{\xi_{i(1)}}{\eta_{i(1)}}+\frac{\xi_{i(2)}}{\eta_{i(2)}}+\ldots+\frac{\xi_{i(k)}}{\eta_{i(k)}}+\ldots
$$

is called a $\left(i_{1}, i_{2}, \ldots, i_{k}, \ldots\right)$ branch of the BCF (2). Let us fix $i(n) \in \mathcal{I}$, then a $\left(i_{1}, i_{2}, \ldots, i_{n}\right)$ branch be a finite branch of the BCF (3). 
Length of a finite $\left(i_{1}, i_{2}, \ldots, i_{n}\right)$ branch of the BCF (3) is a number of partial quotient of the $n$th approximant of the continued fraction (4).

Each branch in the finite BFC (3) has length equal $n$. A figured approximant of the BFC (2) is a BFC that is a part of (2) and has at least two branches with nonequal length. Two types of figured approximants are often used. In particular, $\mathcal{A}$-figured approximants are widely used in proving of formulas of canonical numerators and canonical denominators in a form of a determinant [7], $\mathcal{B}$-figured approximants are used in solving the problem of corresponding betweeen a multiple power series and a BFC.

Let $\frac{a}{b} \equiv \frac{c}{d}$ denotes that $a=c, b=d$.

A $n$th $\mathcal{B}$-figured approximanth of (2) is a BCF

$$
\widehat{f}_{n}=D_{k=1}^{n} \sum_{i_{k}=1}^{2} \frac{\xi_{i(k)}^{*}}{\eta_{i(k)}^{*}}, n \geq 1,
$$

where

$$
\frac{\xi_{i(k)}^{*}}{\eta_{i(k)}^{*}} \equiv \begin{cases}\frac{\xi_{i(k)}}{\eta_{i(k)}}, & \text { if } i_{1}+i_{2}+\ldots+i_{k} \leq n \\ \frac{0}{1}, & \text { if } i_{1}+i_{2}+\ldots+i_{k}>n\end{cases}
$$

The BCF (2) converges ( $\mathcal{B}$-figured converges), if the finite limit of its sequence of approximants $f_{n}$ ( $\mathcal{B}$-figured approximants $\widehat{f}_{n}$ ) exists.

The canonical numerator $A_{n}$ and the canonical denominator $B_{n}$ of the $\mathcal{B}$-figured approximant $\widehat{f}_{n}$ are, respectively, the numerator and the denominator of a calculated BCF $(5), \widehat{f}_{n}=$ $A_{n} / B_{n}$. In calculating we use the following algorithm [7]

$$
\frac{A_{n}}{B_{n}} \equiv \sum_{i_{1}=1}^{2} \frac{\xi_{i(1)}^{*} \eta_{i(1)}^{\prime}}{\eta_{i(1)}^{*} \eta_{i(1)}^{\prime}+\xi_{i(1)}^{\prime}}, n \geq 1,
$$

and

$$
\frac{\xi_{i(m)}^{\prime}}{\eta_{i(m)}^{\prime}} \equiv \sum_{i_{m+1}=1}^{2} \frac{\xi_{i(m+1)}^{*} \eta_{i(m+1)}^{\prime}}{\eta_{i(m+1)}^{*} \eta_{i(m+1)}^{\prime}+\xi_{i(m+1)}^{\prime}}, i(m) \in \mathcal{I}, m=n-1, n-2, \ldots, 1 ; n \geq 2,
$$

where

$$
\xi_{i(n)}^{\prime}=0, \eta_{i(n)}^{\prime}=1, i_{p}=\overline{1,2}, p=\overline{1, n}, n \geq 1
$$

The algorithm (6)-(8) is equivalent to the gradual algorithm of calculation of the BCF (5) without any reductions in the process.

\section{SECTION WITH RESULTS}

Let the $y^{(1)}=\left(1,0, b_{1}, y_{2}^{(1)}, y_{3}^{(1)}, \ldots\right), y^{(2)}=\left(0,1, c_{1}, y_{2}^{(2)}, y_{3}^{(2)}, \ldots\right)$, be the two solutions of equation (1), where the $b_{1}, c_{1}$ are complex numbers. These solutions yield all three linear independent solutions of (1), for example,

$$
y^{(1)}=\left(1,0,0, y_{2}^{(1)}, y_{3}^{(1)}, \ldots\right), y^{(2)}=\left(0,1,0, y_{2}^{(2)}, y_{3}^{(2)}, \ldots\right), y^{(3)}=\left(1,0,1, y_{2}^{(3)}, y_{3}^{(3)}, \ldots\right) .
$$


Put $A_{k}=y_{k}^{(1)}, B_{k}=y_{k}^{(2)}, k=-1,0,1, \ldots$, where

$$
\begin{aligned}
A_{n} & =c_{n} A_{n-1}+b_{n} A_{n-2}+a_{n} A_{n-3}, n=2,3 \ldots, \\
B_{n} & =c_{n} B_{n-1}+b_{n} B_{n-2}+a_{n} B_{n-3}, n=2,3 \ldots,
\end{aligned}
$$

and

$$
A_{-1}=1, A_{0}=0, A_{1}=b_{1}, B_{-1}=0, B_{0}=1, B_{1}=c_{1} .
$$

By analogous with a continued fraction let us construct the BCF such that each its $n$th $\mathcal{B}$-figured approximant equals $A_{n} / B_{n}, n \geq 1$.

If $n=1$ then $A_{1} / B_{1}=b_{1} / c_{1}$. For $n=2$ we have $A_{2} / B_{2}=b_{1} /\left(c_{1}+b_{2} c_{2}^{-1}\right)+a_{1} /\left(c_{2} c_{1}+b_{2}\right)$. If $n \geq 3$ we replace $n$ by $n-1$ in (9) and put the obtained value $A_{n-1}$ in (9), we get

$$
A_{n}=\gamma_{n-1}^{(n)} A_{n-2}+\beta_{n-1}^{(n)} A_{n-3}+\alpha_{n-1}^{(n)} A_{n-4}
$$

where $\gamma_{n-1}^{(n)}=c_{n-1} c_{n}+b_{n}, \beta_{n-1}^{(n)}=b_{n-1} c_{n}+a_{n}, \alpha_{n-1}^{(n)}=a_{n-1} c_{n}$. Next, if $n \geq 4$, by substituting $n-2$ for $n$ in (9) and putting obtained $A_{n-2}$ in (11), we get a new formula for $A_{n}$, etc. If $n \geq r+2$, after $(n-r)$ steps we have

$$
A_{n}=\gamma_{r}^{(n)} A_{r-1}+\beta_{r}^{(n)} A_{r-2}+\alpha_{r}^{(n)} A_{r-3},
$$

where

$$
\gamma_{r}^{(n)}=c_{r} \gamma_{r+1}^{(n)}+\beta_{r+1}^{(n)}, \beta_{r}^{(n)}=b_{r} \gamma_{r+1}^{(n)}+\alpha_{r+1}^{(n)}, \alpha_{r}^{(n)}=a_{r} \gamma_{r+1}^{(n)} \text {, }
$$

$r=n-1, n-2, \ldots, 2$, and $\gamma_{n}^{(n)}=c_{n}, \beta_{n}^{(n)}=b_{n}, \alpha_{n}^{(n)}=a_{n}$.

An analogous relation holds for $B_{n}$

$$
B_{n}=\gamma_{r}^{(n)} B_{r-1}+\beta_{r}^{(n)} B_{r-2}+\alpha_{r}^{(n)} B_{r-3},
$$

where $\gamma_{r}^{(n)}, \beta_{r}^{(n)}, \alpha_{r}^{(n)}, r=n-1, n-2, \ldots, 2$, are defined by (13) and $\gamma_{n}^{(n)}=c_{n}, \beta_{n}^{(n)}=b_{n}$, $\alpha_{n}^{(n)}=a_{n}$, with initial conditions from (10).

Let us introduse the following notation

$$
\begin{aligned}
& c_{k}^{\prime}=c_{k} c_{k-1}+b_{k}, k=\overline{2, n} ; n \geq 2 ; \\
& b_{k}^{\prime}=b_{k} c_{k-2}+a_{k}, k=\overline{3, n} ; n \geq 3 ; \\
& a_{k}^{\prime}=a_{k} c_{k-3}, k=\overline{4, n} ; n \geq 4 ;
\end{aligned}
$$

and

$$
w_{j}^{(n)}=\frac{\beta_{j}^{(n)}}{\gamma_{j}^{(n)}}, j=\overline{1, n}, \quad v_{j}^{(n)}=\frac{c_{j-2} \beta_{j}^{(n)}+\alpha_{j}^{(n)}}{\gamma_{j}^{(n)}}, j=\overline{3, n}, n \geq 3 .
$$

Combining this with the initial conditions (10) and relations (12)-(14), for $r=2$, we obtain

$$
\frac{A_{n}}{B_{n}}=\frac{\gamma_{2}^{(n)} A_{1}+\beta_{2}^{(n)} A_{0}+\alpha_{2}^{(n)} A_{-1}}{\gamma_{2}^{(n)} B_{1}+\beta_{2}^{(n)} B_{0}+\alpha_{2}^{(n)} B_{-1}}=\frac{\gamma_{2}^{(n)} b_{1}+\alpha_{2}^{(n)}}{\gamma_{2}^{(n)} c_{1}+\beta_{2}^{(n)}}=\frac{\beta_{1}^{(n)}}{\gamma_{1}^{(n)}}=w_{1}^{(n)}, n \geq 3 .
$$

Using the denoting (15) and (16) we get

$$
w_{1}^{(n)}=\frac{b_{1}}{c_{1}+w_{2}^{(n)}}+\frac{a_{2} \gamma_{3}^{(n)}}{c_{1}\left(c_{2} \gamma_{3}^{(n)}+\beta_{3}^{(n)}\right)+b_{2} \gamma_{3}^{(n)}+\alpha_{3}^{(n)}}=\frac{b_{1}}{c_{1}+w_{2}^{(n)}}+\frac{a_{2}}{c_{2}^{\prime}+v_{3}^{(n)}} .
$$


Let us prove the recurrent formulas for $w_{k}^{(n)}, k=\overline{2, n-2}, n \geq 4, v_{k}^{(n)}, k=\overline{3, n-2}, n \geq 5$. We obtain

$$
w_{k}^{(n)}=\frac{\beta_{k}^{(n)}}{\gamma_{k}^{(n)}}=\frac{b_{k} \gamma_{k+1}^{(n)}+\alpha_{k+1}^{(n)}}{c_{k} \gamma_{k+1}^{(n)}+\beta_{k+1}^{(n)}}=\frac{b_{k}}{c_{k}+w_{k+1}^{(n)}}+\frac{a_{k+1}}{c_{k+1}^{\prime}+v_{k+2}^{(n)}} .
$$

Analogously

$$
v_{k}^{(n)}=\frac{c_{k-2} \beta_{k}^{(n)}+\alpha_{k}^{(n)}}{\gamma_{k}^{(n)}}=\frac{c_{k-2}\left(b_{k} \gamma_{k+1}^{(n)}+\alpha_{k+1}^{(n)}\right)+a_{k} \gamma_{k+1}^{(n)}}{c_{k} \gamma_{k+1}^{(n)}+\beta_{k+1}^{(n)}}=\frac{b_{k}^{\prime}}{c_{k}+w_{k+1}^{(n)}}+\frac{a_{k+1}^{\prime}}{c_{k+1}^{\prime}+v_{k+2}^{(n)}}
$$

Let us now consider the case $k=n-1$

$$
w_{n-1}^{(n)}=\frac{b_{n-1}}{c_{n-1}+\frac{b_{n}}{c_{n}}}+\frac{a_{n}}{c_{n}^{\prime}}, n \geq 2, v_{n-1}^{(n)}=\frac{b_{n-1}^{\prime}}{c_{n-1}+\frac{b_{n}}{c_{n}}}+\frac{a_{n}^{\prime}}{c_{n}^{\prime}}, n \geq 4
$$

If we put $w_{n}^{(n)}=\frac{b_{n}}{c_{n}}, v_{n}^{(n)}=\frac{b_{n}^{\prime}}{c_{n}}, w_{n+1}^{(n)}=v_{n+1}^{(n)}=0, w_{n+2}^{(n)}=v_{n+2}^{(n)}=\infty$ we have that recurrent formulas (17), (18) hold for $k=n-1, n$, as well.

Consider the BCF (2), where

$$
\xi_{1}=b_{1}, \xi_{2}=a_{2}
$$

and for all $i(k) \in \mathcal{I}, k \geq 2$

$$
\xi_{i(k)}= \begin{cases}b_{i_{1}+i_{2}+\ldots+i_{k^{\prime}}} & \text { if } i_{k-1}=i_{k}=1 \\ b_{i_{1}+i_{2}+\ldots+i_{k^{\prime}}}^{\prime} & \text { if } i_{k-1}=2, i_{k}=1 \\ a_{i_{1}+i_{2}+\ldots+i_{k^{\prime}}} & \text { if } i_{k-1}=1, i_{k}=2 \\ a_{i_{1}+i_{2}+\ldots+i_{k^{\prime}}}^{\prime} & \text { if } i_{k-1}=2, i_{k}=2\end{cases}
$$

and for all $i(k) \in \mathcal{I}, k \geq 1$

$$
\eta_{i(k)}= \begin{cases}c_{i_{1}+i_{2}+\ldots+i_{k^{\prime}},} & \text { if } i_{k}=1 \\ c_{i_{1}+i_{2}+\ldots+i_{k^{\prime}}}^{\prime} & \text { if } i_{k}=2\end{cases}
$$

where the $a_{i}, b_{i}, c_{i}, i \geq 1$, are coeficients of (1), the $a_{i+2}^{\prime}, b_{i+1}^{\prime}, c_{i}^{\prime}, i \geq 2$, are obtained from (15).

Theorem 1. Let $\left\{A_{n}\right\},\left\{B_{n}\right\}$ be sequences of complex numbers such that

$$
A_{-1}=1, A_{0}=0, A_{1}=b_{1}, B_{-1}=0, B_{0}=1, B_{1}=c_{1},
$$

and

$$
\begin{gathered}
A_{n}=c_{n} A_{n-1}+b_{n} A_{n-2}+a_{n} A_{n-3}, n=2,3 \ldots, \\
B_{n}=c_{n} B_{n-1}+b_{n} B_{n-2}+a_{n} B_{n-3}, n=2,3 \ldots,
\end{gathered}
$$

where the $a_{n}, b_{n}, c_{n}, n \geq 1$, are complex constants. Then the $A_{n}, B_{n}$ are the canonical numerator and the canonical denominator of $n$th $\mathcal{B}$-figured approximant of the $B C F(2)$, i.e. $\widehat{f}_{n}=A_{n} / B_{n}$. 
Proof. Applying the equality $A_{n} / B_{n}=w_{1}^{(n)}, n \geq 1$, we use the recurrent relations (17)-(19) and step by step write the value $A_{n} / B_{n}$ in a form of a finite BCF that is equal $\widehat{f}_{n}$. On the first step we have

$$
\frac{A_{n}}{B_{n}}=\frac{b_{1}}{c_{1}+w_{2}^{(n)}}+\frac{a_{2}}{c_{2}^{\prime}+v_{3}^{(n)}}=\frac{\xi_{1}}{\eta_{1}+w_{2}^{(n)}}+\frac{\xi_{2}}{\eta_{2}+v_{3}^{(n)}} .
$$

After the second step we get

$$
\frac{A_{n}}{B_{n}}=\frac{\xi_{1}}{\eta_{1}+\frac{\xi_{1,1}}{\eta_{1,1}+w_{3}^{(n)}}+\frac{\xi_{1,2}}{\eta_{1,2}+v_{4}^{(n)}}}+\frac{\xi_{2}}{\eta_{2}+v_{3}^{(n)}}
$$

and after the third step we obtain

$$
\frac{A_{n}}{B_{n}}=\frac{\xi_{1}}{\eta_{1}+\frac{\xi_{1,1}}{\eta_{1,1}+\frac{\xi_{1,1,1}}{\eta_{1,1,1}+w_{4}^{(n)}}+\frac{\xi_{1,1,2}}{\eta_{1,1,2}+v_{5}^{(n)}}}+\frac{\xi_{1,2}}{\eta_{1,2}+v_{4}^{(n)}}}+\frac{\xi_{2}}{\eta_{2}+\frac{\xi_{2,1}}{\eta_{2,1}+w_{4}^{(n)}}+\frac{\xi_{2,2}}{\eta_{2,2}+v_{5}^{(n)}}},
$$

etc. Using the method of mathematical induction we prove that after $m$ steps, $1<m<n$, we get

$$
\frac{A_{n}}{B_{n}}=D_{k=1}^{m} \sum_{i_{k}=1}^{2} \frac{\xi_{i(k)}^{*}}{\eta_{i(k)}^{*}}
$$

where $\xi_{i(k)}^{*}=\xi_{i(k)}$, if $i_{1}+i_{2}+\ldots+i_{k} \leq m$ or $i_{1}+i_{2}+\ldots+i_{k}=m+1$ and $i_{k}=2$; if $i_{1}+i_{2}+\ldots+i_{k} \leq m-1$, then $\eta_{i(k)}^{*}=\eta_{i(k)}$; if $i_{k}=1$ and $i_{1}+i_{2}+\ldots+i_{k}=m$, then $\eta_{i(k)}^{*}=\eta_{i(k)}+w_{m+1}^{(n)}$; if $i_{k}=2$ and $i_{1}+i_{2}+\ldots+i_{k}=m$, then $\eta_{i(k)}^{*}=\eta_{i(k)}+v_{m+1}^{(n)}$; if $i_{k}=2$ and $i_{1}+i_{2}+\ldots+i_{k}=m+1$, then $\eta_{i(k)}^{*}=\eta_{i(k)}+v_{m+2}^{(n)}$. In all other cases $\frac{\xi_{i(k)}^{*}}{\eta_{i(k)}^{*}} \equiv \frac{0}{1}$.

Let us make the next, $m+1$, step. Let $i_{1}+i_{2}+\ldots+i_{k}=m, i_{k}=1$, then

$$
\eta_{i(k)}^{*}=\eta_{i(k)}+w_{m+1}^{(n)}=\eta_{i(k)}+\frac{b_{m+1}}{c_{m+1}+w_{m+2}^{(n)}}+\frac{a_{m+2}}{c_{m+2}^{\prime}+v_{m+3}^{(n)}}
$$

or by using (21), (22) we obtain

$$
\eta_{i(k)}^{*}=\eta_{i(k)}+\frac{\xi_{i(k), 1}}{\eta_{i(k), 1}+w_{m+2}^{(n)}}+\frac{\xi_{i(k), 2}}{\eta_{i(k), 2}+v_{m+3}^{(n)}} .
$$

If $i_{1}+i_{2}+\ldots+i_{k}=m, i_{k}=2$, then

$$
\begin{aligned}
\eta_{i(k)}^{*}=\eta_{i(k)}+v_{m+1}^{(n)} & =\eta_{i(k)}+\frac{b_{m+1}^{\prime}}{c_{m+1}+w_{m+2}^{(n)}}+\frac{a_{m+2}^{\prime}}{c_{m+2}^{\prime}+v_{m+3}^{(n)}} \\
& =\eta_{i(k)}+\frac{\xi_{i(k), 1}}{\eta_{i(k), 1}+w_{m+2}^{(n)}}+\frac{\xi_{i(k), 2}}{\eta_{i(k), 2}+v_{m+3}^{(n)}} .
\end{aligned}
$$


If $i_{1}+i_{2}+\ldots+i_{k}=m+1, i_{k}=2$, then $\eta_{i(k)}^{*}=\eta_{i(k)}+v_{m+2}^{(n)}$.

Hense, we get the equality (23), where $m$ is replaced by $m+1$.

Put $m=n-1$. Then, using the equalities (19) we obtain that $\eta_{i(k)}^{*}=\eta_{i(k)}+\frac{\xi_{i(k), 1}}{\eta_{i(k), 1}}$ if $i_{1}+i_{2}+\ldots+i_{k}=n-1$, and $\eta_{i(k)}^{*}=\eta_{i(k)}$ if $i_{1}+i_{2}+\ldots+i_{k}=n, i_{k}=2$.

Thus,

$$
\frac{A_{n}}{B_{n}}=D_{k=1}^{n} \sum_{i_{k}=1}^{2} \frac{\xi_{i(k)}^{*}}{\eta_{i(k)}^{*}}=\widehat{f}_{n} .
$$

Remark 1. A BCF with two branches of branching with arbitrary complex elements

$$
D_{k=1}^{\infty} \sum_{i_{k}=1}^{2} \frac{\alpha_{i(k)}}{\beta_{i(k)}}
$$

can not be transformed into the form (2), where the $\xi_{i(k)}, \eta_{i(k)}, i(k) \in \mathcal{I}$, are determined by formulas (20)-(22). For calculating canonical numerators and canonical denominators of a $B C F$ with $N$ branches of branching, $N>1$, the linear recurrent relations do not hold.

Let us consider the $n$th $\mathcal{B}$-figured approximants of BCF (24) and (2). Let $n=2$, then we get second $\mathcal{B}$-figured approximant of the BCF (24) $\widehat{g}_{2}=\alpha_{1} /\left(\beta_{1}+\alpha_{1,1} \beta_{1,1}^{-1}\right)+\alpha_{2} / \beta_{2}$, and by using the formulas (20)-(22) and (15) we obtain second $\mathcal{B}$-figured approximant of the BCF (2) $\widehat{f}_{2}=$ $b_{1} /\left(c_{1}+b_{2} c_{2}^{-1}\right)+a_{2} /\left(c_{1} c_{2}+b_{2}\right)$. If we put $b_{1}=\alpha_{1}, c_{1}=\beta_{1}, a_{2}=\alpha_{2}, b_{2}=\alpha_{11}, c_{2}=\beta_{12}$, then we get that the relation $\beta_{1} \beta_{12}+\alpha_{11}=\beta_{2}$ must hold. But the $\beta_{2}$ is arbitrary. Hense, this is the case that illustrates the truth of the Remark 1.

Theorem 2. Let the coefficients $a_{n}, b_{n}, c_{n}, n \geq 2$, of equation (1) be positive real numbers such that

$$
\sum_{k=2}^{\infty} \mu_{k}=\infty
$$

where

$$
\begin{aligned}
\mu_{k} & =\min _{k \leq j \leq 2 k}\left\{\frac{M_{j}}{R_{j+1}}, \frac{M_{j+1}}{R_{j+2}^{\prime}}\right\}, \quad k \geq 2, \\
M_{j} & =c_{j} c_{j}^{\prime} c_{j+1} c_{j+2}^{\prime}, \quad j \geq 2, \\
R_{j} & =b_{j} c_{j-1}^{\prime} c_{j+1}^{\prime}+a_{j+1} c_{j-1} c_{j}, \quad j \geq 3, \\
R_{j}^{\prime} & =b_{j}^{\prime} c_{j-1}^{\prime} c_{j+1}^{\prime}+a_{j+1}^{\prime} c_{j-1} c_{j}, \quad j \geq 4,
\end{aligned}
$$

and $a_{i+2}^{\prime}, b_{i+1}^{\prime}, c_{i}^{\prime}, i \geq 2$, are determited by (15). Then the BCF (2), whose elements satisfy relations (20)-(22), $\mathcal{B}$-figured converges.

Proof. Let us show that the elements of the BFC (2) satisfy the conditions of the Theorem 3.11 [7, p. 85]. For this, we consider the following expressions $d_{i(k+1)}=\eta_{i(k)} \eta_{i(k+1)} / \xi_{i(k+1)}, i(k+1) \in$ $\mathcal{I}, k \geq 2$. If we fix $i(k-1) \in \mathcal{I}, k \geq 2$, using the relations (21), (22), we obtain

$$
d_{i(k-1), 1,1}=\frac{c_{j} c_{j+1}}{b_{j+1}}, d_{i(k-1), 2,1}=\frac{c_{j+1} c_{j+2}}{b_{j+2}^{\prime}}, d_{i(k-1), 1,2}=\frac{c_{j}^{\prime} c_{j+2}^{\prime}}{a_{j+2}}, d_{i(k-1), 2,2}=\frac{c_{j+1}^{\prime} c_{j+3}^{\prime}}{a_{j+3}^{\prime}},
$$


where $j=\sum_{l=1}^{k-1} i_{l}+1$. From this we obtain

$$
\begin{aligned}
\min _{i(k+1) \in \mathcal{I}, k \geq 2}\left\{d_{i(k+1)}\right\} & =\min _{k \leq j \leq 2 k, k \geq 2}\left\{\frac{c_{j} c_{j+1}}{b_{j+1}}, \frac{c_{j+1} c_{j+2}}{b_{j+2}^{\prime}}, \frac{c_{j}^{\prime} c_{j+2}^{\prime}}{a_{j+2}}, \frac{c_{j+1}^{\prime} c_{j+3}^{\prime}}{a_{j+3}^{\prime}}\right\} \\
& \geq \min _{k \leq j \leq 2 k, k \geq 2}\left\{\frac{M_{j}}{R_{j+1}}, \frac{M_{j+1}^{\prime}}{R_{j+2}^{\prime}}\right\}=\mu_{k} .
\end{aligned}
$$

Now from (25) it follows that the elements of the BFC (2) satisfy the conditions of the Theorem 3.11 [7, p. 85]. This means that the BFC (2) converges.

Finally, by the Theorem $2.2[7$, p. 48], the BFC (2) $\mathcal{B}$-figured converges.

\section{REFERENCES}

[1] Antonova T.M., Bodnar D.I. Convergence region of branched continued fractions of special form. Approx. Theor. and its Appl.: Prog. Inst. Math. NAS Ukr. 2000, 31, 19-32. (in Ukrainian)

[2] Antonova T.M., Sus O.M. Necessary conditions of convergence for one class of two-dimensional continued fractions with complex elements. Approx. Theor. and Rel. Probl.: Pr. Inst. Matem. NAS Ukr. 2015, 12 (4), 8-28. (in Ukrainian)

[3] Baran O.E. Some circular regions of convergence for branched continued fractions of a special form. J. Math. Sci. 2015, 205 (4), 491-500. doi:10.1007/s10958-015-2262-3

[4] Baran O.E. Some convergence regions of branched continued fractions of a special form. Carpathian Math. Publ. 2013, 5 (1), 4-13. doi:10.15330/cmp.5.1.4-13 (in Ukrainian)

[5] Bodnar D.I., Bilanyk I.B. Convergence criterion for branched continued fractions of the special form with positive elements. Carpathian Math. Publ. 2017, 9 (1), 13-21. doi:10.15330/cmp.9.1.13-21

[6] Bodnar D.I., Bilanyk I.B. On convergence of branched continued fractions of the special form in ungular domains. Mat. Metodi Fiz.-Mekh. Polya 2017, 60 (3), 60-69. (in Ukrainian)

[7] Bodnar D.I. Branched continued fractions. Naukova Dumka, Kyiv, 1986. (in Russian)

[8] Bodnar D.I., Zatorskyi R.A. Generalization of continued fractions. II. J. Math. Sci. 2012, 184, (1), 46-55. doi:10.1007/s10958-012-0851-y

[9] Bodnar D.I., Kuchminska Kh.Yo. Development of the theory of branched continued fractions in 1996-2016. J. Math. Sci. 2016, 231 (4), 481-494. doi:10.1007/s10958-018-3828-7

[10] Bodnar O.S., Dmytryshyn R.I. On the convergence of multidimensional S-fractions with independent variables. Carpathian Math. Publ. 2018, 10 (1), 58-64. doi:10.15330/cmp.10.1.58-64

[11] Bodnarchuk P.I., Skorobogatko V.Ya. Branched continued fractions and its application. Naukova Dumka, Kyiv, 1974. (in Ukrainian)

[12] de Bruin M.G. Convergence of Generalized C-fractions. J. Approx. Theory 1978, 24, 177-207.

[13] Dmytryshyn R.I. Convergence of some branched continued fractions with independent variables. Mat. Stud. 2017, 47 (2), 150-159. doi:10.15330/ms.47.2.150-159

[14] Fürshtenau E. Üeber Kettenbrüche höherer Ordnung. Jahrbuch über die Forschritte der Mathematik, 1876, 133135. (in German)

[15] Jones W.B., Thron W.J. Continued fractions:Analytic theory and applications. London; Amsterdam; Don Mills; Ontario; Sydney; Tokyo: Addison-Wesley Pub. Co., Inc, 1980.

[16] Krukovskyi B.V. On the theory of continued fractions of second class. J. Inst. Math. NAS Ukr. 1933, 1, 195-206. (in Ukrainian) 
[17] Kuchminska Kh.Yo. Two-dimensional continued fractions. Pidstryhach Institute for Appl. Probl. in Mech. and Math. NAS of Ukraine, Lviv, 2010. (in Ukrainian)

[18] Lorentzen L., Waadeland H. Continued Fractions. Vol.1: Convergence Theory., 2d ed. Amsterdam: Atlantis Press; World Scientific, 2008.

[19] Perron O. Die Lehre von den Kettenbrüchen. Bd.II:Analytisch-funktinentheoretische Kettenbrüche., 3e aufl. Stuttgart: B.G.Teubner Verlagsgesellschaft, 1957. (in German)

[20] Siemaszko W. Branched continued fractions for double power series. J. Comput. Appl. Math. 1980., 6 (2), 121-125.

[21] Skorobogatko V.Ya. The theory of branched continued fractions and its application in computational mathematics. Nauka, Moscow, 1983. (in Russian)

Received 02.05.2019

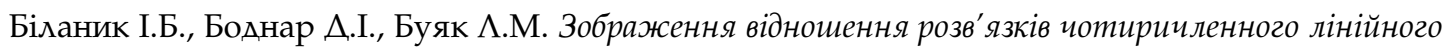
рекурентного співвідношення у вигляді гіллястого ланиюгового дробу // Карпатські матем. публ. — 2019. — T.11, №1. — С. 33-41.

Відношення двох лінійно незалежних розв'язків чотиричленного лінійного рекурентного співвідношення за аналогією з неперервними дробами представлено у вигляду гіллястого ланцюгового дробу з двома гілками розгалуження. Знайдено формули частинних чисельників та частинних знаменників цього гіллястого ланцюгового дробу. Розв'язки різницевого рівняння $€$ канонічними чисельниками і канонічними знаменниками $\mathcal{B}$-фігурних піАхіАних дробів. Часто використовують два типи фігурних підхідних дробів: $\mathcal{A}$-фігурні і $\mathcal{B}$-фігурні. $n$-ий $\mathcal{A}$ фігурний підхідний дріб гіллястого ланцюгового дробу отримується додаванням наступної частинної частки Ао $(n-1)$-го $\mathcal{A}$-фігурного піАхіАного дробу. $n$-ий $\mathcal{B}$-фігурний піАхіАний дріб гіллястого ланцюгового Аробу є гіллястий ланцюговий Аріб, що $є$ його частиною і містить всі ті елементи, сума індексів яких менша, або рівна $n$. $\mathcal{A}$-фігурні підхідні дроби використовуються при доведенні формул для канонічних чисельників і знаменників у вигляді визначників, $\mathcal{B}$-фігурні підхідні дроби - у задачах відповідності між кратними степеневими рядами і гіллястими ланцюговими дробами. Загальний гіллястий ланцюговий дріб не можна звести до побудованого гіллястого ланцюгового дробу. Аля обчислення канонічних чисельників і канонічних знаменників гіллястих ланцюгових дробів з $N, N>1$, гілками розгалуження не справджуються лінійні рекурентні співвідношення. Аосліджена $\mathcal{B}$-фігурна збіжність побудованого дробу у випадку, коли коефіцієнтами рекурентного співвідношення є дійсні додатні числа.

Клюиові слова і фрази: гіллястий ланцюговий дріб, рекурентне співвідношення. 